\title{
SISTEM PENDUKUNG KEPUTUSAN PEMILIHAN KOTA TUJUAN WISATA WILAYAH JAWA BALI MENGGUNAKAN METODE AKSIDENTAL SAMPLING (STUDI KASUS DI GRAS TOUR AND TRAVEL YOGYAKARTA)
}

\author{
Ismi Yuniati, Anton Setiawan, Yuliani Indrianingsih \\ Jurusan Teknik Informatika \\ Sekolah Tinggi Teknologi Adisutjipto \\ informatika@stta.ac.id
}

\begin{abstract}
Tourist attraction in Indonesia is one of the natural resources to be proud. That we need an alternative build Decision Support System Application. This application shows can assist determine the potential tourist travel destination, make memorable and accordance with the characteristics potential tourists addition this application saves the time and effort find a tourist destination because it can be accessed anywhere. The final result steps by steps, the best obtained from two respondents are Afriani 105 for the city of Yogyakarta and Damar 84 for the city of Sukabumi. Based on these results, system is able to determine built the city as desired tourist destination and tourist characteristics.
\end{abstract}

Keywords : Decision Support Systems, Selection Tourist Destination, Accidental Sampling Method.

\section{Latar Belakang}

GRAS Tour and Travel Yogyakarta merupakan suatu perusahaan yang bergerak di bidang pariwisata yaitu travel agent. Banyak sekali faktor yang harus dipertimbangkan dalam menentukan perjalanan wisata yang terpenting adalah sesuai keinginan dan karakteristik dari wisatawan agar liburannya lebih berkesan.

\section{Tinjauan Pustaka}

a. Analisis Intensitas Kunjungan Wisata Obyek Wisata Air Terjun Linggahara Kabupaten Labuhanbatu Sumatera Utara oleh Ria Resti Fuas Canti, Toti Indrawati dan Deny Setiawan Fakultas Ekonomi Universitas Riau 6 Juli 2013.

b. Pengembangan Sistem Pendukung Keputusan Untuk Penilaian Ujian Tugas Skripsi oleh Hanif Al Fatta Stmik Amikon Yogyakarta.

\section{Metode Aksidental Sampling}

Metode aksidental sampling yaitu teknik pengambilan sampel berdasarkan pada kemudahan dan sampel dapat dipilih karena berada pada waktu, situasi, dan tempat yang tepat. Sesuai dengan permasalahan penelitian yang telah dikemukakan teknik analisis yang digunakan analisis deskriptif dan kuantitatif. Analisisa kuantitatif bersifat deskriptif yang dilakukan sesuai dengan tujuan penelitian dengan menggambarkan atau menguraikan secara jelas apa yang ada di lapangan disertai dengan perbandingan-perbandingan dan analisis scoring dengan metode pembobotan. 


\section{Rumus Aksidental Sampling \\ total skor $=\sum w i * \mathrm{k} i$ \\ wi $=$ bobot kriteria ki (nilai kriteria $a d m i n)$ \\ $\mathrm{ki}=\mathrm{kriteria} \mathrm{ki}$ (nilai prioritas pengguna)}

Penentuan jumlah sampel dihitung menggunakan rumus Slovin sebagai berikut:

$\mathrm{n}=\frac{\mathrm{N}}{1+\mathrm{Ne}^{2}}$

$\mathrm{n}=$ ukuran sampel

$\mathrm{N}=$ ukuran populasi

$\mathrm{e}=$ nilai kritis (batas ketelitian) yang diinginkan (persen kelonggaran ketidak telitian karena kesalahan pengambilan sample populasi).

\section{Diagram Konteks}

Penggunaan diagram alir data bertujuan memudahkan dalam melihat arus data dalam sistem. Diagram alir data hanya mempunyai dua entitas yaitu admin dan anggota. Pada sistem ini, admin melakukan manipulasi data ke dalam sistem dan sistem memberikan feedback informasi kepada admin sedangkan anggota juga memasukkan kriteria permintaan kepada sistem dan sistem akan memberikan feedback informasi atau kota wisata sesuai permintaan anggota.

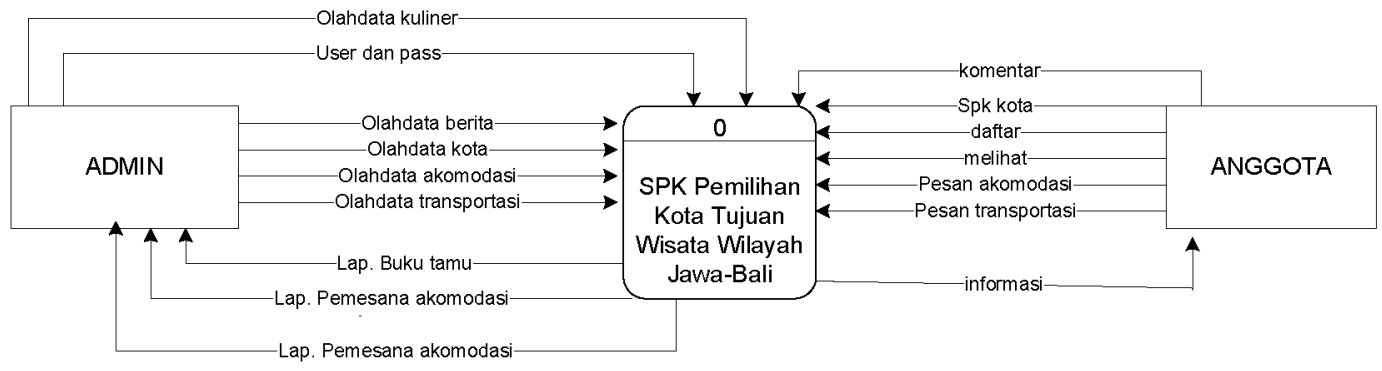

Gambar 1 Diagram Konteks

\section{Flowchart pengguna spk wisata}

Dalam flowchart ini pengguna memulai lalu menginputkan data ke dalam sistem, jika pengguna telah selesai melakukan input data lalu masuk ke dalam proses validasi sesuai rumus yang ada pada metode, setelah proses validasi akan muncul output.

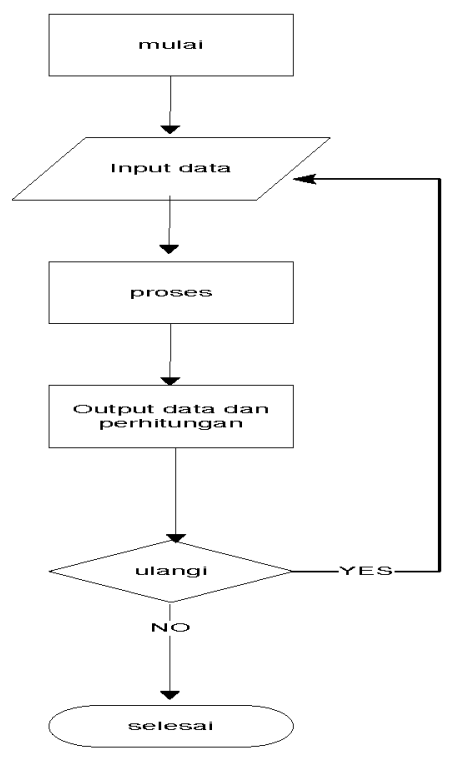

Gambar 2 Flowchart Pengguna SPK Wisata 


\section{Entity Relatioship Diagram (ERD)}

Entity Relationship Diagram digunakan untuk memodelkan struktur data dan hubungan antara data satu dengan data yang lain, dimana terdapat sembilan data yang yang terhubung dan satu tidak terhubung yaitu admin karena tidak mempengaruhi hasil dari sistem.

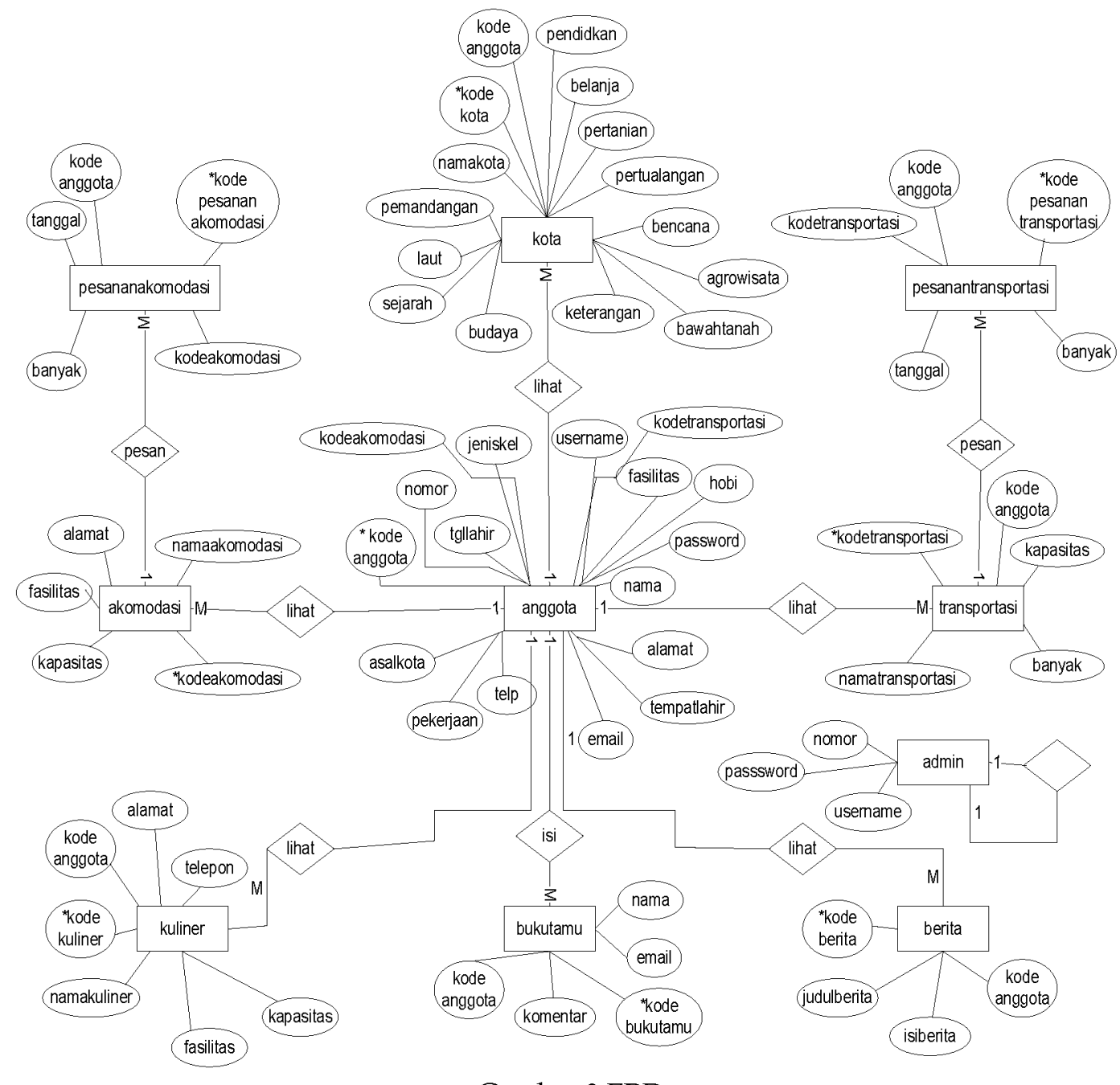

Gambar 3 ERD

\section{Logical Read Structure (LRS) / Tabel Relasi}

Dalam Logical Read Structure menggambarkan relasi antar tabel - tabel dalam satu database dimana terdapat hubungan antara primary key dan foreign key yang menghubungkan tabel satu dengan yang lainnya sehingga tabel yang direlasikan dapat berhubungan. 


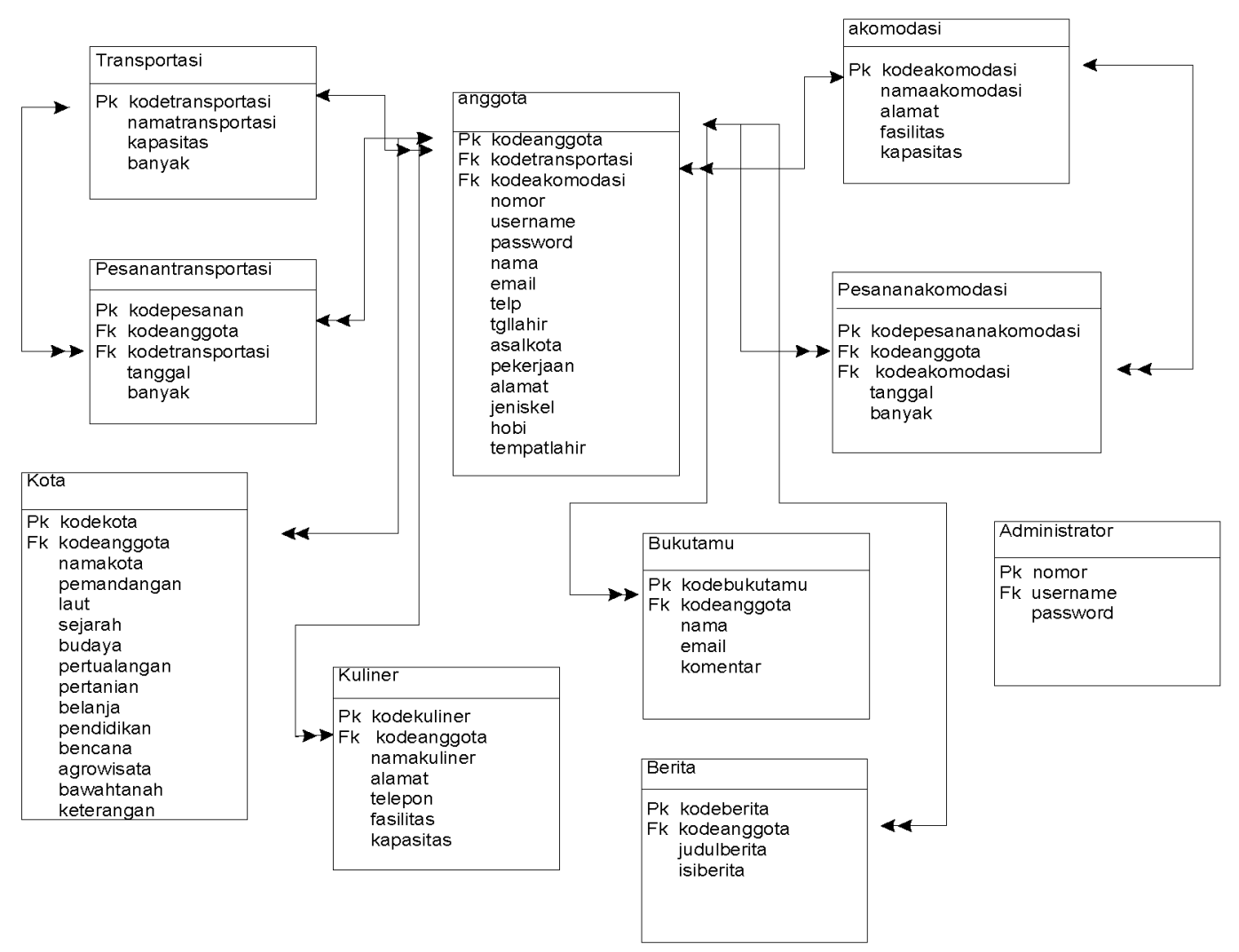

Gambar 4 Tabel Relasi

\section{Keterangan:}

Pk : Primary Key

Fk : Foreign Key

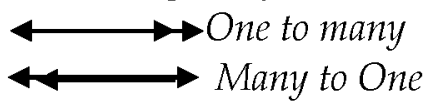

\section{Perancangan Aplikasi}

Adapun perancangan aplikasi pada sistem pendukung keputusan pemilihan kota wisata di wilayah Jawa- Bali dengan metode aksidental sampling, kriteria yang digunakan terdiri dari:

1. Pemandangan

2. Laut

3. Sejarah

4. Budaya

5. Pertanian

6. Pertualangan

7. Pendidkan

8. Belanja

9. Bencana

10. Agrowisata

11. Bawah tanah

Prioritas Pemilihan

Admin memasukkan nilai dari karakteristik kedalam sistem sebgai bobot nilai prioritas sebagai berikut :

5 = sangat penting sekali 
$4=$ sangat penting

$3=$ biasa

2 = tidak penting

$1=$ sangat tidak penting

Sedangkan pengguna memamsukkan nilai yang kebalikan dari admin daftar nilai prioritasnya sebagai berikut:

1 = sangat penting sekali

2 = sangat penting

$3=$ biasa

$4=$ tidak penting

5 = sangat tidak penting

Untuk menghitung skor nilai total yaitu

Skor nilai total : nilai prioritas admin * nilai prioritas user

Hasilnya ditampilkan semua, lalu diurutkan dari nilai perkalian tertinggi dan tiga hasil perkalian tertinggi sebagai output.

\section{Implementasi Sistem}

Tahap implementasi sistem merupakan tahap pendiskripsian suatu sistem aplikasi agar sistem aplikasi tersebut siap untuk dioperasikan.

\section{Tampilan awal SPK wisata}

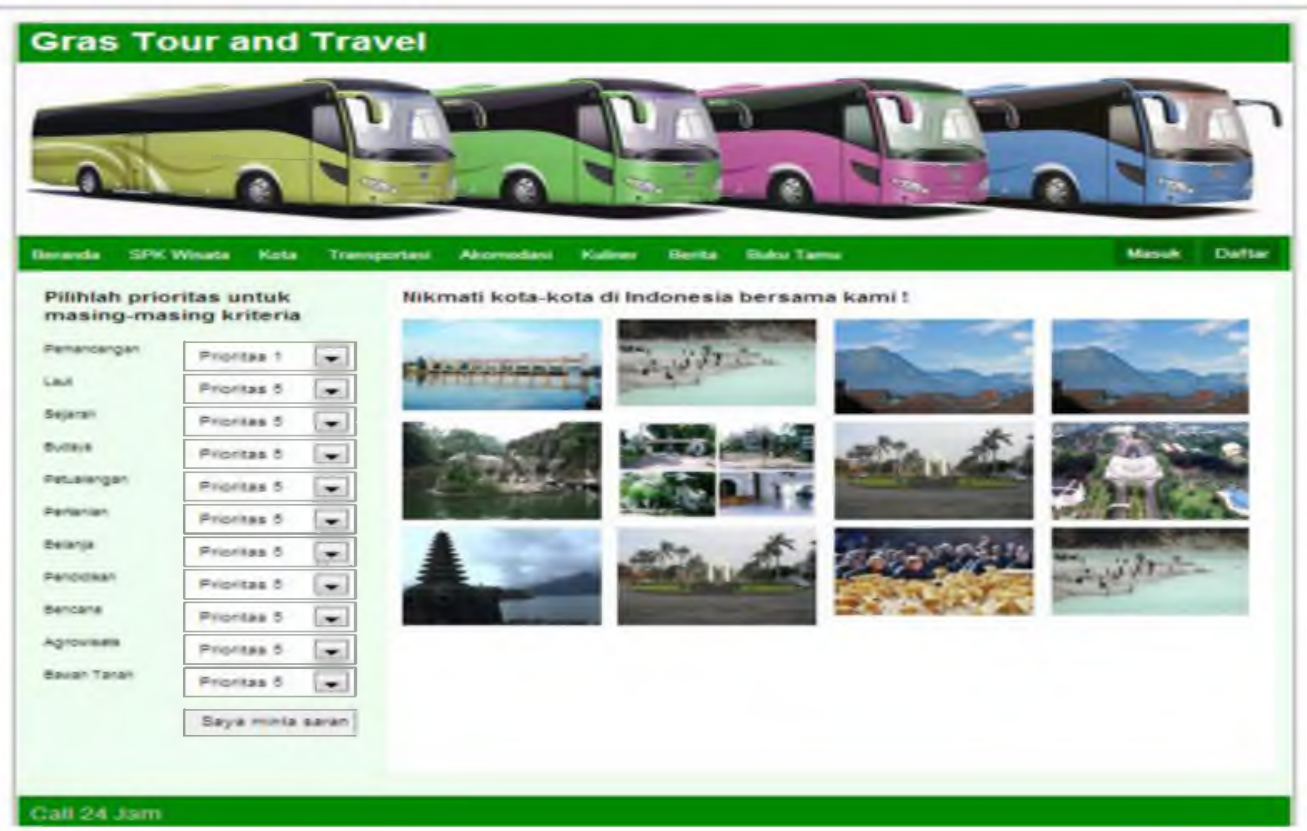

Gambar 5 Tampilan Awal SPK Wisata

Gambar 5 berisi tentang karakteristik jenis wisata yang harus diinputkan oleh calon wisawan dapat yang akan meminta saran dan gambar tempat wisata. 


\section{Tampilan Saran SPK.}

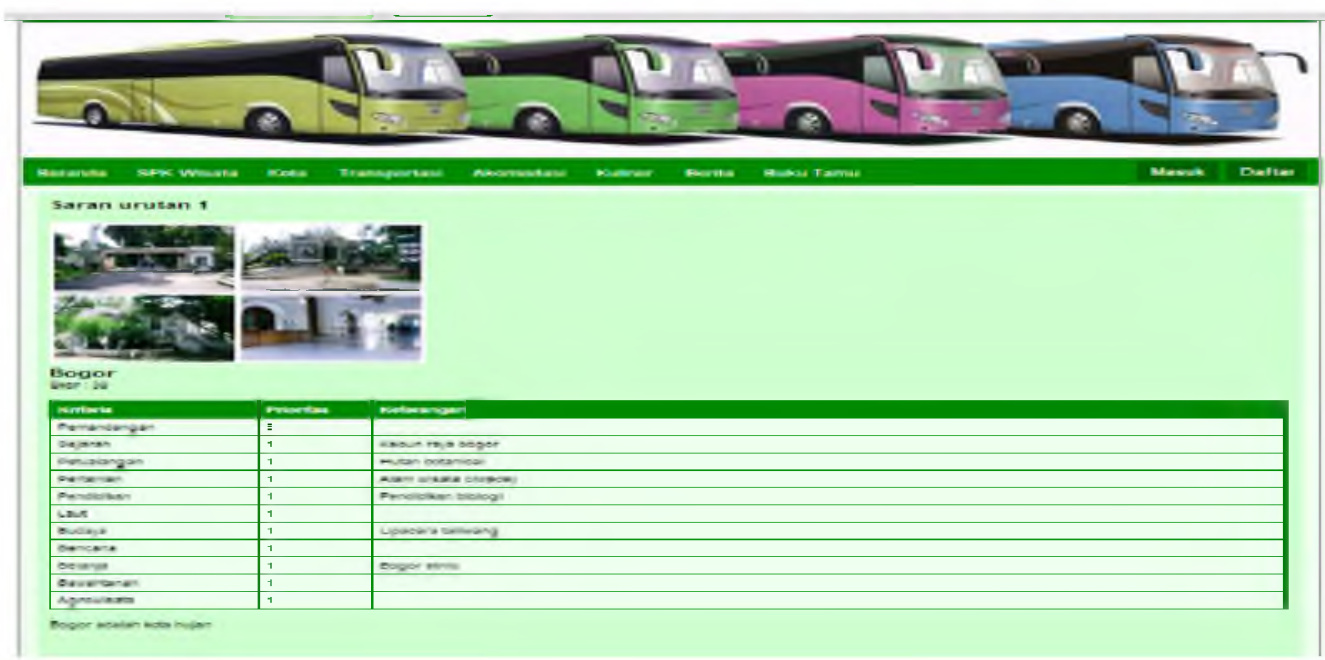

Gambar 6 Tampilan Saran SPK

Pada Gambar 6 menunjukkan tiga teratas hasil kota tujuan wisata sesuai dengan keinginan calon wisatawan.

\section{Tampilan perhitungan SPK}

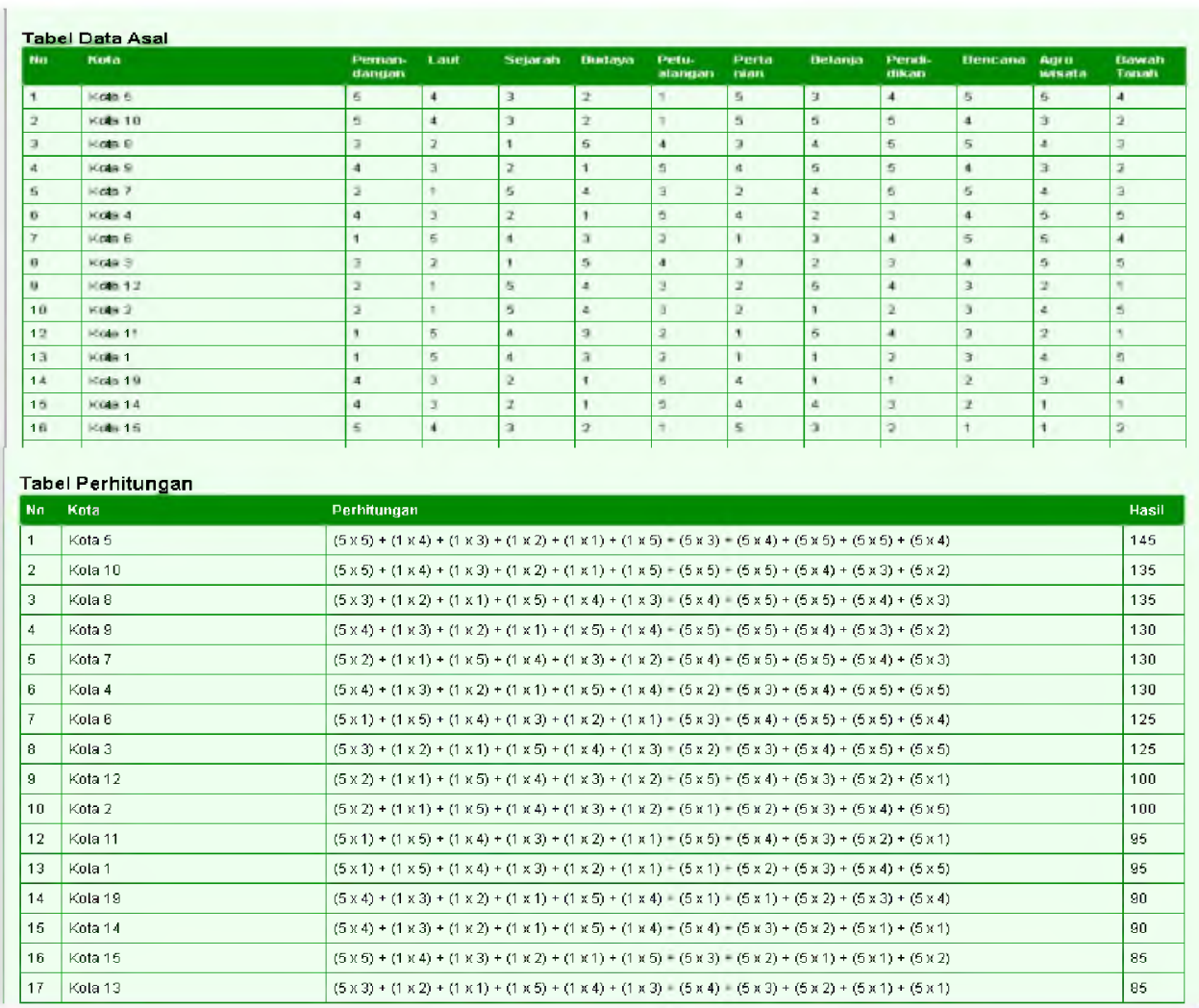

Gambar 7 Perhitungan SPK

Pada Gambar 7 perhitungan SPK dapat ditampilkan jika calon wisatawan menghendaki untuk melihat hasil perhitungan kenapa diperoleh kota tujuan wisata yang dimaksud. 


\section{Form Admin}

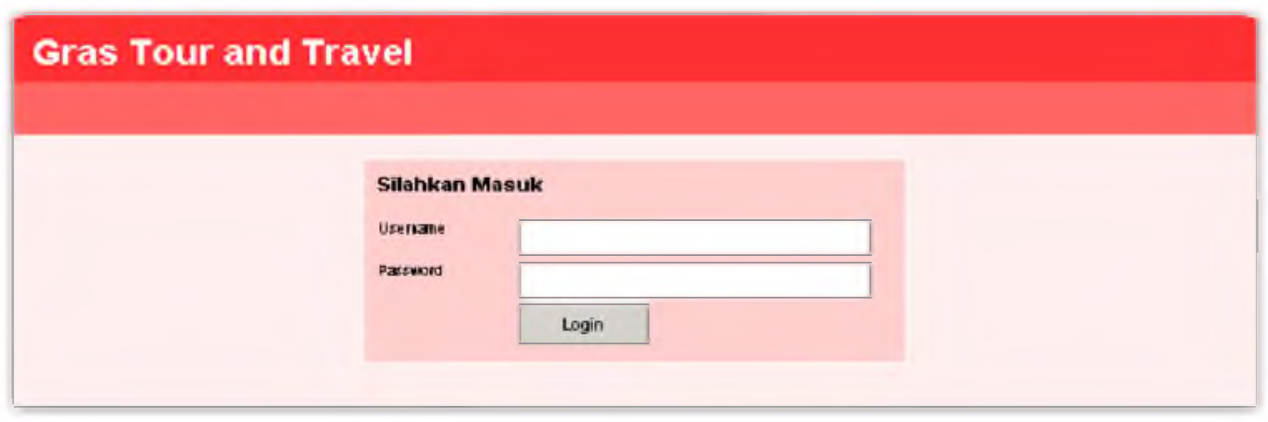

Gambar 8 Form Admin

Pada Gambar 8 Untuk admin melakukan manipulasi data harus memasukkan username dan password.

\section{Form pengelolaan kota}

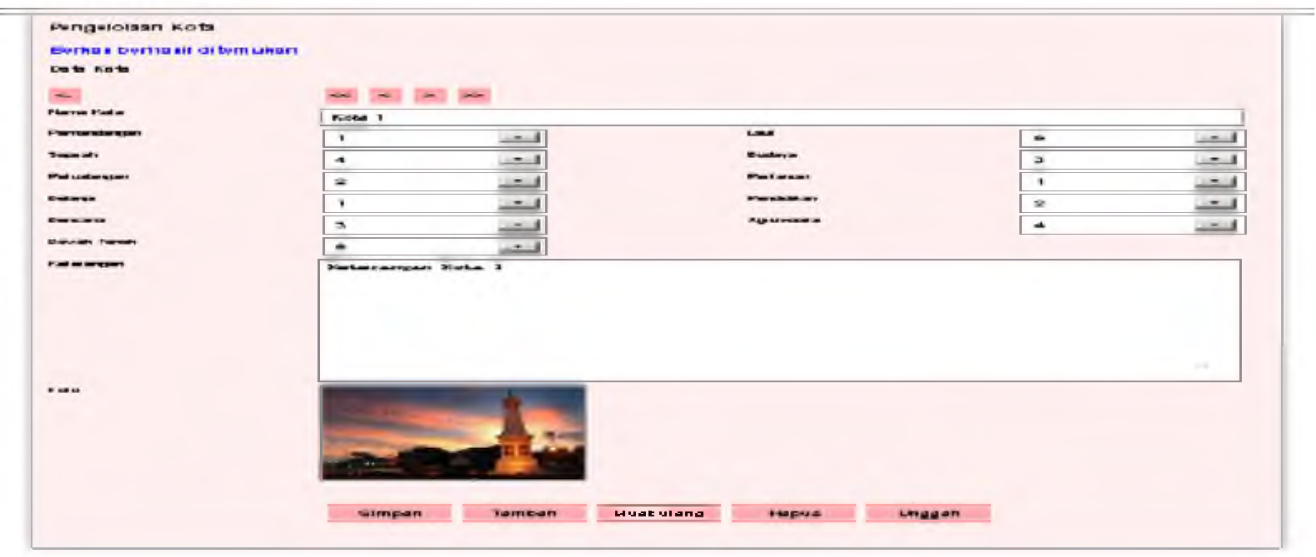

Gambar 9 Form Pengelolaan Kota

Pada Gambar 9 form ini berisi bobot SPK yang ditentukan oleh admin pada setiap kota yang diinputkan.

\section{Kesimpulan}

Berdasarkan uji coba dan analisis maka dapat diambil kesimpulan :

1. Sistem Pendukung Keputusan Pemilihan Kota Tujuan Wisata merupakan solusi bagi para calon wisatawan dalam menentukan kota tujuan wisata berdasarkan minat dan karakteristik wisatawan.

2. Metode Aksidental Sampling merupakan metode yang cocok digunakan untuk menentukan kota tujuan wisata karena hasilnya sangat mendekati keinginan calon wisatawan untuk memilih kota dalam berwisata.

3. Sistem Pendukung Keputusan ini bermanfaat bagi calon wisatawan agar dapat merencanakan paket tujuan wisata kemana akan berlibur sesuai dengan keinginan dan membuat liburan lebih berkesan.

\section{Saran}

1. Sistem ini dapat dikembangkan dengan metode lain agar hasilnya bisa lebih akurat. 
2. Aplikasi perlu dikembangkan dengan menambahkan video promosi pariwisata agar lebih menarik pengunjung.

\section{DAFTAR PUSTAKA}

Al Fatta, Hanif, 2009, Pengembangan Sistem Pendukung Keputusan Untuk Penilaian Tugas Skripsi, STMIK Amikon Yogyakarta JURNAL DASI, ISSN: 1411-3201 Vol. 10 No. 1 Maret 2009.

HM.Jogiyanto, 2005, Analisis dan Desain Sistem Informasi: Pendekatan Teori dan Praktek Aplikasi Bisnis, Yogyakarta : CV. Andi Offset.

Hadi Sabari Yunus, 2006, Metodologi Penelitian Wilayah Kontemporer, Yogyakarta : Graha Ilmu.

Indrawati, 2013, Analisis Intesitas Kunjungan Wisata Obyek Wisata Air Terjun Linggahara Kabupaten Labuhanbatu Sumatera Utara Fakultas Ekonomi Universitas Sumatera Utara JURNAL SOSIAL EKONOMI PEMBANGUNAN Tahun II No. 6, Juli 2012.

Kristanto, Andri, 2004, Rekayasa Perangkat Lunak (Konsep Dasar), Yogyakarta : Penerbit Gava Media.

Prasetyo., Al-Bahra, 2005, Analisis dan Desain Sistem Informasi:, Yogyakarta : Graha Ilmu.

Zulganef, 2006, Metode Penelitian Sosial dan Bisnis, Yogyakarta : Graha Ilmu. 